DOI 10.37882/2223-2982.2020.08.22

\title{
ОПЫТ РАБОТЫ В ЭЛЕКТРОННОЙ ИНФОРМАЦИОННО-ОБРАЗОВАТЕЛЬНОЙ СРЕДЕ
}

\section{EXPERIENCE IN ELECTRONIC INFORMATION AND EDUCATIONAL ENVIRONMENT}

\section{G. Kuchumova}

Summary: The article attempts to briefly analyze the advantages and disadvantages of functioning in the electronic information environment of the main structural elements of educational activities. The implementation of the requirements of the Federal state educational standard in the conditions of self-isolation has formed a new teaching experience that needs to be systematically comprehended and cognitively evaluated. Subsequent professional practice should take into account the changes that have occurred, both in the field of education and in society.

Keywords: life safety, electronic information and educational environment, technical means, information technologies, Autonomous mode, activity, communication, method.
$\mathrm{H}$ овая объективная реальность, в которой мы одномоментно оказались, выявила и поставила перед всеми ряд проблем, вопросов, противоречий. Ограниченное время на адаптацию, достаточно жёсткие условия ускорили процесс их разрешению и преодолению. Несколько месяцев погружения в другой формат обучения - электронную информационно-образовательную среду, позволяют обобщить первый полученный опыт и обратить внимание на объективные и субъективные трудности, с которыми мы столкнулись.

Образовательная деятельность традиционно представляется системой, включающей в себя документ, обучающихся, преподавателей и материально-техническое обеспечение.

Системообразующим элементом являются документы, прежде всего федеральные законы, федеральные государственные образовательные стандарты, учебные планы. Под электронным обучением понимается организация образовательной деятельности с применением содержащейся в базах данных и используемой при реализации образовательных программ информации и обеспечивающих ее обработку информационных технологий, технических средств, а также информационно-телекоммуникационных сетей, обеспечивающих передачу по линиям связи указанной информации, взаимодействие обучающихся и педагогических работников. [2]
Кучумова Галина Владимировна

Старший преподаватель, ФГБОУ ВО «ГАУ Северного

Зауралья», г. Тюмень

galina0602galina@yandex.ru

Аннотация: В статье предпринята попытка кратко проанализировать преимущества и несовершенства функционирования основных структурных элементов образовательной деятельности в электронной информационной среде. Реализация требований федерального государственного образовательного стандарта в условиях режима самоизоляции сформировала новый опыт преподавательской работы, который необходимо системно осмыслить и когнитивно оценить. Последующая профессиональная практика должна осуществляться с учётом изменений, произошедших, как в сфере образования, так и в обществе.

Ключевые слова: безопасность жизнедеятельности, электронная информационно-образовательная среда, технические средства, информационные технологии, автономный режим, деятельность, коммуникация, метод.

Действующий стандарт указывает, что информационно-коммуникационная технология - это информационные процессы и методы работы с информацией, осуществляемые с применением средств вычислительной техники и средств телекоммуникации [3]. В условиях режима повышенной готовности и самоизоляции материально-техническое обеспечение образовательного процесса преимущественно находилось вне зоны управления и регулирования образовательного учреждения. Проблемы, возникшие в данном элементе системы, очевидны: информационно-телекоммуникационные сети не всегда способствовали качественному проведению лекционных и практических занятий, достаточно часто и студенческая, и преподавательская аудитории обменивались сообщениями о невозможности подключения, отсутствии устойчивого сетевого трафика, и многих других сложностях. Фактическое техническое оснащение и сопровождение процесса проведения лекций и практических занятий в условиях режима самоизоляции из полномочий образовательного учреждения перешло в обязанности преподавателей и обучающихся, усугубив непростые условия работы и обучения. Кроме того, этот период показал, что не все студенты и преподаватели готовы работать с техническими устройствами в необходимом, требуемом графике, а наличие одного компьютера в семье недостаточно, если дети обучаются, а родители работают удаленно. Другие гаджеты не способны помочь в данной ситуации, учитывая спектр, сложность выполняемых задач и временные ограничения. К со- 
жалению, преимущественно, эти негативные моменты и трудности преодолевались без активного участия работодателя, усилиями преподавателей и обучающихся. Контроль качества проведения занятий осуществлялся регулярно, а помощь, понимание и поддержку оказывали, в основном, семья и коллеги.

Парадигма «обучающийся-преподаватель» является самым устойчивым элементом указанного порядка. Пожалуй, некорректно оценивать сложившуюся ситуацию с позиций обучающихся, но можно констатировать, что не все студенты расположены продолжать или осуществлять обучение вне аудитории. Связано это с личностными характеристиками, уровнем подготовки, мотивацией, отсутствием традиционного «административного давления» и многими другими аспектами. Электронная образовательная среда предоставляет широчайший спектр возможностей для реализации различных по уровню, сложности, тематике и проблематике заданий. Она несёт массу преимуществ обучающимся: возможность работать в своем комфортном режиме и графике, безусловно, сообразуясь с расписанием, шанс определять приоритеты, последовательность, наполнение реализуемых заданий. Кроме того, колоссальный массив информации, позволяет проявить творческие и когнитивные наклонности, и выходить за рамки традиционных студенческих презентаций и рефератов. Важным является и то, что работа в электронной образовательной среде позволяет углубиться в решаемую задачу или выполняемое задание и не отвлекаться на традиционные помехи, существующие в студенческой аудитории. Парадокс заключается в том, что упомянутые преимущества для некоторых обучающихся оказались препятствием к успешному освоению учебного материала и выполнению требований образовательного стандарта. «Свободный» график был воспринят, оценён и успешно освоен наиболее ответственными и дисциплинированными из числа обучающихся. Отсутствие традиционного контроля и пристального внимания со стороны преподавателя не позволило некоторым студентам своевременно, в требуемом объеме и качестве выполнять задания в рамках учебного плана. Большое количество разнообразных информационных ресурсов не было востребовано и применено в процессе изучения определенных тем и вопросов. Для кого-то проблемой оказалось отсутствие сокурсников, готовых всегда поддержать и быстро подсказать. Обучение в автономном режиме - это довольно специфичный вид деятельности, требующий от студентов не только навыков уверенного и свободного взаимодействия с электронными ресурсами и техническими системами, но и коммуникаций с преподавателем и студенческим коллективом, а также собранности и в определенном смысле трудовой дисциплины.

Преподавательская деятельность в новом формате представляется достаточно сложной и напряжённой.
Модель подготовки будущего инженера включает в себя ряд последовательных этапов и элементов, к которым, безусловно, относят активное использование средств информационных технологий, автоматизации, включая знания о фундаментальных исследованиях и ожидаемых результатах в производственной деятельности [4]. В рамках реализуемого образовательного стандарта и учебного плана в курсе безопасности жизнедеятельности аудиторными занятиями являются лекционные и практические. Проведение лекции в on-line, безусловно, вызывает сложности в случае большого количества ежедневных лекций и отсутствии обратной связи с обучающимися в силу технических или коммуникационных причин. Традиционная лекция предполагает более активное визуальное и вербальное взаимодействие преподавателя и студенческой аудитории. Обучающиеся могут задавать вопросы, включаться в обсуждения и дискуссии, уточнять спорные или непонятные моменты. Преподаватель, свободно владеющий информационным массивом в рамках учебной дисциплины, в процессе чтения лекции акцентирует внимание слушателей на ключевых вопросах, повторяет и разъясняет сложные и наиболее значимые аспекты. Получая отклик на излагаемый теоретический материал, лектор может не только контролировать восприятие и понимание аудитории, но и оценивать востребованность, значимость и важность лекции. Практические занятия, давно освоенные и успешно проводимые в аудитории, потребовали существенной корректировки в изложении информации, ее оформлении, предоставлении обучающимся и мониторинге результатов. Работы, в обычном режиме проводимые с приборами с целью оценки заданных параметров или характеристик, были переведены в новый формат и несколько утратили свою привлекательность для определенной части студенческой аудитории, предпочитающей когнитивные и аналитические задания. Расчетные задания и оформление работ выполнялись с большим трудом, вниманием, терпением и потребовали дополнительных дидактических материалов. Вопросы, возникающие в студенческой аудитории, разрешаются, как правило, мгновенно, а новый способ взаимодействия преподавателя и студента не позволял доступно и быстро ответить каждому.

Следует отметить, что опыт, приобретенный в течение этого сложного, неоднозначного периода будет осмыслен, обобщен и транслирован в корректировку, прежде всего, методов преподавания дисциплины «Безопасность жизнедеятельности» от объяснительно-иллюстративного и репродуктивного к эвристическому и исследовательскому методам. Изменения требуются и лекционному курсу, необходимо сбалансировать объем, информативность, актуальность и наглядность предлагаемой информации. Большинство обучающиеся достаточно активно и заинтересованно занимались в электронной среде, используя навыки работы с контен- 
том, поэтому большее внимание следует уделить проектным и исследовательским заданиям, позволяющим формировать культуру безопасности с учётом требований ФГОС.

\section{ЛИТЕРАТУРА}

1. Российская Федерация. Законы. 06 информации, информационных технологиях и о защите информации (с изменениями и дополнениями) [Текст]: Федеральный закон от 27 июля 2006г.N 149-Ф3 Режим доступа: https://base.garant.ru/12148555/

2. Российская Федерация. Законы. 06 образовании в Российской Федерации [Текст]: Федеральный закон от 29 декабря 2012г. N 272-Ф3 Режим доступа: https://base.garant.ru/70291362/

3. ГОСТ Р 52653-2006 Информационно-коммуникационная технологии в образовании. Термины и определения. [Tекст]: Режим доступа: http://docs.cntd.ru/ document/1200053103

4. Клопотной А.Ю., Мелякова 0.А. Психофизиологические аспекты профессиональной самореализации инженера в условиях современного производства // Современная наука: актуальные проблемы теории и практики. Серия: Гуманитарные науки. - 2019. -N 7-2. - С. $28-30$

5. Натхо 0.И. Электронно-образовательная среда как главный действующий элемент смешанного обучения // Научно-методический электронный журнал «Концепт». - 2014. - Т. 26. - C. 121-125. - URL: http://e-koncept.ru/2014/64325.htm.

\footnotetext{
○ Кучумова Галина Владимировна (galina0602galina@yandex.ru ).
}

Журнал «Современная наука: актуальные проблемы теории и практики»

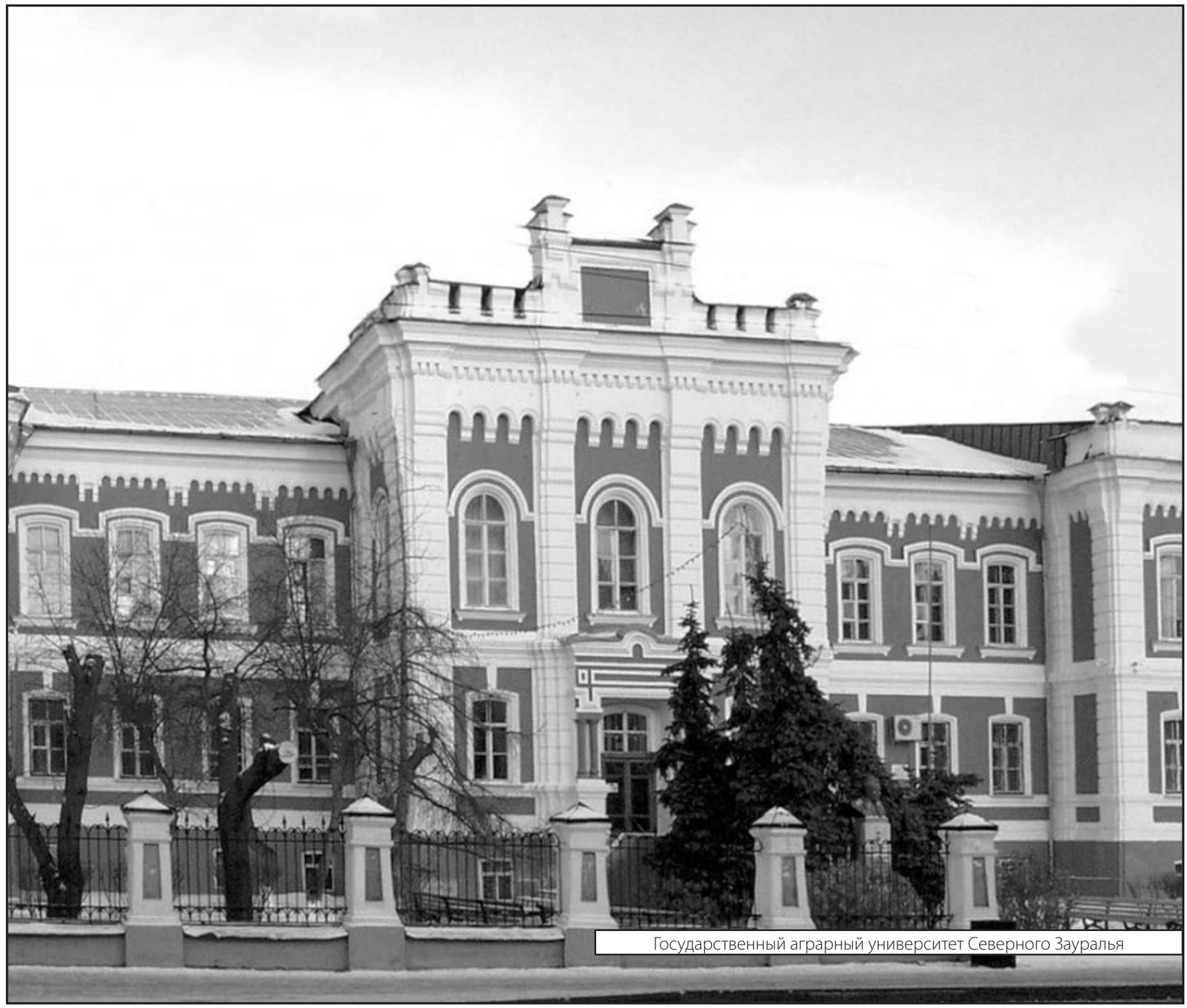

